\title{
Manuais de
}

\section{Educomunicação: subsídios das organizações sociais e da política pública}

Ismar de Oliveira Soares

Professor titular da Universidade de São Paulo, coordenador do Núcleo de Comunicação e Educação da USP (NCE-USP) e da Licenciatura em Educomunicação da Escola de Comunicações e Artes da mesma universidade. É presidente da ABPEducom (Associação Brasileira de Pesquisadores e Profissionais em Educomunicação).

E-mail: ismarolive@yahoo.com

Daniele Próspero

Mestre em Ciências da Comunicação pela Universidade de São Paulo (USP), jornalista, especialista em jornalismo social e em educação comunitária. É sócia-fundadora da ABPEducom (Associação Brasileira de Pesquisadores e Profissionais em Educomunicação).

E-mail: danieleprospero@gmail.com

Resumo: $\bigcirc$ artigo analisa três sistematizações, denominadas "Manuais de Educomunicação", que apresentam experiências, reflexões e práticas de programas e projetos voltados para o tema da educomunicação, tanto na educação não formal quanto no complexo espaço da educação formal. Os suportes midiáticos são roteiros para o desenvolvimento de ações similares, destinando-se às organizações sociais, escolas, instituições e pessoas interessadas em promover, com coerência e criatividade, práticas educomunicativas.

Palavras-chave: manuais, educomunicação, práticas, metodologia, guia.
Abstract: The paper analyses three systematizations, denominated "Educommunication Manuals", which present experiences, reflexions and practices of the programs and projects oriented to the educommunication subject, both in non-formal and formal education. The medium are guidelines to the development of similar actions, provided for social organizations, schools, institutions and people who are interested in promoting, coherently and creatively, educommunicative practices.

Keywords: manuals, educommunications, practices, methodology, guideline.

\section{INTRODUÇÃO}

À medida que o conceito de Educomunicação ganha legitimidade e vem sendo adotado por um número crescente de organizações não governamentais (ONG) ou mesmo por instituições públicas e privadas do ensino, sistematizações 
1. O conceito Educomunicação foi empregado pela primeira vez em 1999, para designar o conjunto das ações voltadas ao planejamento, desenvolvimento de ecossistemas comunicativos abertos e democráticos nos espaços educativos, mediante projetos de intervenção social mediados pelas linguagens da comunicação, tendo como meta a promoção do direito de expressão e o pleno exercício da cidadania (SOARES, 1999). Anteriormente, o termo era usado esporadicamente, por organizações como a Unesco, para identificar ações relativas a procedimentos voltados a educar frente ao impacto dos meios de comunicação.

2. VOLPI, Mário; PALAZZO, Ludmila (orgs.). Mudando sua escola, mudando sua comunidade, melhorando o mundo! Sistematização da Experiência em Educomunicação. Brasília: Unicef, 2010. e subsídios relativos a experiências sobre a aplicação do conceito vêm sendo produzidos, convertendo-se em roteiros para a reflexão dos que se propõem a implantar programas e projetos voltados para o tema, tanto na educação não formal quanto no complexo espaço da educação formal.

Por seu caráter instrucional, denominamos tais subsídios, para efeito desta súmula, como "Manuais de Educomunicação". Identificamos, para análise, três desses suportes midiáticos produzidos no final da primeira década em que o termo passara a designar um tipo peculiar de intervenção social na interface Comunicação/Educação ${ }^{1}$. Produzidos para atender objetivos específicos, os relatos configuram-se em guias de fácil manuseio, pois se encontram disponibilizados na internet, para acesso e impressão.

Dos manuais resenhados, dois documentam o caminho educomunicativo percorrido por organizações não governamentais (Manual Unicef/Rede CEP e Guia de Educomunicação), enquanto o terceiro (Caderno Comunicação e Uso de Mídias) traduz o esforço do poder público federal em dar sustentação teórico-metodológica ao macrocampo "Comunicação e Uso de Mídias”, previsto no Programa Mais Educação, do Ministério da Educação (MEC). São eles:

\section{MANUAL UNICEF/REDE CEP - SISTEMATIZAÇÃO DE EXPERIÊNCIA EM EDUCOMUNICAÇÃO (BRASÍLIA, 2010)²}

O projeto "Mudando sua escola, mudando sua comunidade, melhorando o mundo!" foi desenvolvido, no final da primeira década do século XXI, com adolescentes de escolas públicas de São Paulo (SP), Rio de Janeiro (RJ), Salvador (BA), Belo Horizonte (MG) e Fortaleza (CE). A iniciativa envolveu seis instituições vinculadas à Rede CEP - Comunicação, Educação e Participação, tendo sido articulada pelo Unicef, contando com o patrocínio financeiro da iniciativa privada.

O objetivo geral da iniciativa foi o de desenvolver e sistematizar o exercício da prática educomunicativa mediada por organizações não governamentais junto a professores e estudantes de escolas públicas, em diferentes contextos. As ações ocorreram entre 2009 e 2010. O texto, de 125 páginas, conta com a organização final de Mário Volpi e Ludmila Palazzo (Unicef).

\section{Estrutura do material}

A sistematização conta, além da Apresentação e da Bibliografia, com seis capítulos. Dois tratam dos referenciais teóricos (O que é Educomunicação? e Comunicação e Educação, uma Questão de Direito); dois outros narram as experiências de implantação das práticas educomuncativas em escolas públicas (A Iniciativa e Lições Aprendidas da Educomunicação); um texto analisa a Educomunicação como desafio para as políticas públicas (Do Local ao Global). A obra se encerra apresentando um Guia Metodológico. 


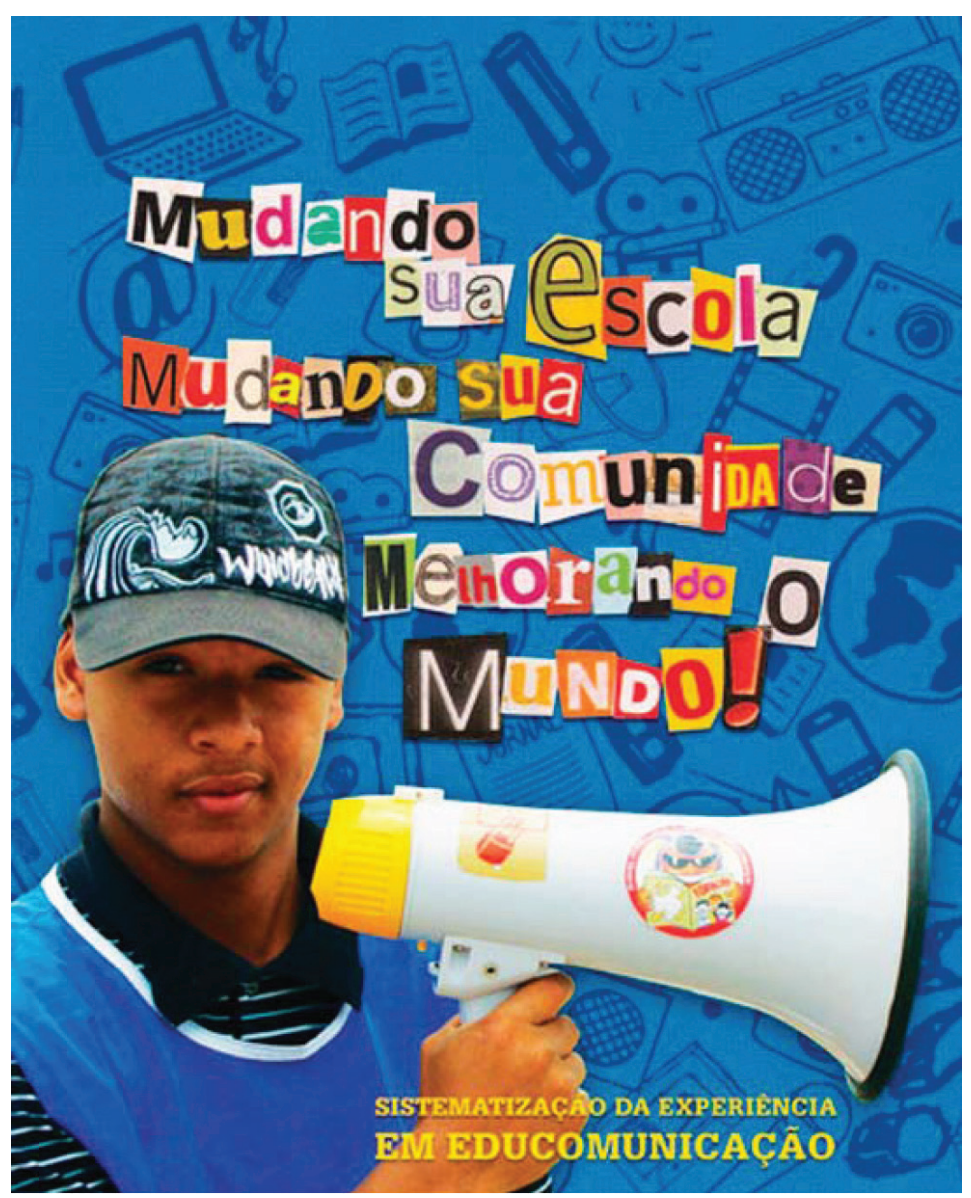

$\mathrm{Na}$ Apresentação, o manual descreve o conceito de Educomunicação a partir da contribuição de autores latino-americanos, avisando: "A proposta educomunicativa dos projetos aqui envolvidos está calcada firmemente na voz dos estudantes, ou seja, na criação de novos espaços de diálogo na escola e na comunidade". Os diferentes trabalhos desenvolvidos apresentaram como resultados: a formação cidadã dos educandos, a desconstrução das relações de poder na escola e na comunidade e o alinhamento entre organizações especializadas em Educomunicação e o poder público.

A descrição detalhada de cada resultado permite entender que não se trata de mera inovação educativa. O que se revela, nessas experiências, é uma aprendizagem coletiva sobre os possíveis caminhos para a conquista, pelos jovens, de um direito fundamental, que é o direito à expressão. Em termos metodológicos, os relatos apontam para práticas de reconhecimento do ambiente, base para o planejamento das ações, chegando a modelos criativos de inserções na realidade, contando, para tanto, com a mediação das TIC (Tecnologias da Informação e Comunicação), na perspectiva de uma gestão compartilhada dos recursos da informação. Os processos são alimentados pelos mesmos princípios: a busca do protagonismo comunicativo da criança e do adolescente, em íntima colaboração com os professores e gestores escolares. 


\section{Relatos}

O manual se enriquece com o relato das experiências promovidas em sintonia em cinco capitais brasileiras:

1 (São Paulo, SP). O primeiro relato une à Associação Cidade Escola Aprendiz e à ONG Viração numa proposta de ação educomunicativa com alunos do $5^{\circ}$ ao $7^{\circ}$ ano do ensino fundamental, em escola pública, na região do Grajaú, na cidade de São Paulo. A meta do trabalho foi o fortalecimento da relação dos adolescentes com o território do entorno escolar, implementando ações comunicativas comunitárias planejadas e executadas coletivamente, em favor da prática da sustentabilidade. $\mathrm{O}$ foco da metodologia utilizada foi o planejamento compartilhado das ações comunicativas, incluindo uma campanha com o envolvimento das famílias.

2o (Rio de Janeiro, RJ). O segundo relato, voltado expressamente para o uso das tecnologias numa perspectiva estratégica, é apresentado pelo Centro de Criação de Imagem Popular (Cecip), do Rio de Janeiro. A preocupação do Cecip não era a de garantir aos alunos o domínio dos recursos, mas a de oferecer uma formação para que soubessem usá-las politicamente, colocando-os a serviço de ações de transformação da sociedade. A criatividade no uso das TIC é o forte desta experiência.

3ำ (Salvador, BA). O relato da Cipó - Comunicação Interativa informa que o projeto a seu cargo desenvolveu-se junto a adolescentes de uma escola pública da cidade de Salvador, visando a criação de um Núcleo Interativo (NI) formado por estudantes de séries distintas. Teve como objetivo oportunizar a participação de diferentes alunos numa ação comum, propiciando o convívio das distintas idades, além de promover a integração ente eles. A metodologia seguida foi a da produção midiática por meio de diferentes linguagens. A Cipó preocupou-se com o que, na teoria da Educomunicação, denomina-se como gestão democrática e compartilhada dos processos comunicativos no espaço escolar.

4- (Belo Horizonte, MG). O quarto relato foi produzido pela Oficina de Imagens, de Belo Horizonte. Já envolvida, à longa data, com as políticas públicas de educação no município, a organização buscou relacionar-se com projetos já existentes que pudessem dialogar com o conceito de Educomunicação. Foi o caso do Comunic@Escola!, a partir do qual a organização, após realizar um diagnóstico sobre as condições de leitura e escrita dos alunos a serem atendidos, passou a trabalhar tanto no espaço da escola com oficinas midiáticas, quanto na relação dos alunos com a comunidade, por meio da construção, pelos adolescentes, de mapas de suas trajetórias pela cidade, destinadas a identificar equipamentos públicos de cultura onde os jovens pudessem interagir com o ambiente. 
5ำ (Fortaleza, CE). O quinto relato veio de Fortaleza, elaborado pela ONG Comunicação e Cultura, especializada em trabalhar com a metodologia do jornal escolar. O objetivo do Projeto "Jornal Fala Escola" - que chegou a 127 escolas, onde foram produzidos 77 mil exemplares de publicações impressas, envolvendo aproximadamente mil alunos/ano - foi fornecer às escolas uma ferramenta maleável, de uso transversal, como um portador de textos, que dá uso social à escrita.

\section{O que ficou}

O "Manual da Unicef/Rede CEP" aponta para a importância da criação de rotinas de trabalhos com os adolescentes. Ressalta a figura de um educomunicador de referência no processo de mobilização da comunidade. Quanto às políticas públicas no setor, lembra, como lição, a importância do diálogo com os gestores públicos, dadas as peculiaridades de cada situação. Em outras palavras, ao lado de uma coerência epistemológica (a preservação dos fundamentos do conceito), uma flexibilização metodológica se faz necessária para que se chegue ao público - sempre numeroso - constituído pelos jovens servidos pelas redes públicas de educação.

Em termos de orientação para a prática cotidiana, o Guia Metodológico, ao final, sintetiza os passos seguidos pelas cinco experiências, trazendo as sequências das atividades voltadas à mobilização dos alunos em torno às práticas educomunicativas. Descreve com pormenores os roteiros para as produções midiáticas, dando especial atenção ao jornal e à rádio escolar³.

\section{GUIA DE EDUCOMUNICAÇÃO - CONCEITOS E PRÁTICAS DA VIRAÇÃO (SÃO PAULO, 2010) ${ }^{4}$}

Conhecida no Brasil e no exterior, por sua capacidade de articular jovens em torno do fazer comunicativo, a ONG Viração Educomunicação notabilizou-se pela busca de uma coerência epistemológica entre o pensar e o produzir. Na verdade, o ideário educomunicativo que justificou a sistematização do conceito pelo NCE-USP, em 1999, encontra nos programas da Viração um espaço de exercício e experimentação permanentes.

O "Guia de Educomunicação" baseia-se, justamente, nas referências que deram sustentação aos projetos promovidos desde a fundação da entidade. Foi a forma encontrada pelos seus promotores - jovens profissionais da comunicação, liderados pelo jornalista Paulo Lima, em articulação com adolescentes e jovens dos mais diferentes cantos do país - de disponibilizar, em benefício da coletividade, o caminho percorrido em uma década de ações e reflexões educomunicativas.
3. Disponível em: <www. unicef.org/brazil/pt/resources_19415.htm>.

4. VIRAÇÃO. Guia de Educomunicação - Conceitos e práticas. São Paulo: 2010. 
Nesse sentido, o guia destina-se às organizações sociais, escolas, instituições e pessoas interessadas em desenvolver, com coerência e criatividade, práticas educomunicativas junto à juventude.

\section{Estrutura do material}

O material traz oito temas centrais, reunidos em capítulos. Sendo eles:

a) A história da Viração e a carta de princípios e valores da entidade pela ótica dos adolescentes.

b) Os conceitos de comunicação integral e da comunicação não violenta.

c) A visão da Viração sobre a importância da garantia das políticas públicas voltadas para as crianças e adolescentes a partir da voz deles próprios.

d)A metodologia utilizada nos encontros nacionais que Viração realiza com a participação de adolescentes, jovens e colaboradores de Conselhos Jovens da ONG.

e) Apresentação das pautas políticas das quais a Viração participa e apoia, como as propostas da Conferência Nacional de Juventude, da Conferência Nacional de Comunicação, a Política Nacional de Saúde da Pessoa com Deficiência, a Convenção Internacional sobre os Direitos de Crianças e Adolescentes e o Estatuto da Criança e do Adolescente.

f) Compartilhamento dos principais debates a respeito da comunicação como um direito humano, apresentando conceitos como comunicação compartilhada.

g) Discussão a respeito do conceito de Educomunicação utilizado como base das ações da Viração, assim como o papel do educomunicador.

h) E, por fim, algumas estratégias de comunicação e mobilização utilizadas pela organização.

\section{Temáticas abordadas}

O guia ressalta, logo no início, que a teoria e a prática da Viração estão aprofundando o humanismo enfatizado pelo educador Paulo Freire no campo da Comunicação, ou seja, as iniciativas da organização visam ver a pessoa na sua totalidade existencial. A ideia não é aprender apenas a usar antigas e novas tecnologias, meios e instrumentos de comunicação. A meta é "ser mais".

O ponto de participação passa a ser, então, a comunicação integral. O termo visa ressaltar a importância de se trabalhar de forma sistêmica e holística a Educomunicação. Com isso, é possível ver as interconexões entre os diversos saberes e ambientes. Outro ponto central é a Comunicação Não Violenta (CNV), ou seja, parar para ouvir o outro e compreender o que se passa dentro dele por trás das palavras, quais são seus sentimentos e suas necessidades. A pergunta passa a ser: "Será que a gente consegue se reeducar para um mundo que não 
induza à culpa, à vergonha, a conceitos de obrigação e de dever?". Ou: "Como agir apenas a partir da opção de dar e receber naturalmente?”.

O guia destaca ainda a importância de se garantir, nas práticas educomunicativas, a participação, pois esta permite fazer o que está ao alcance das mãos, a fim de transformar o presente e o futuro. E destaca: "Quanto maior a participação das pessoas, dentro da família, na escola, no bairro, na cidade ou no país, mais chances teremos de garantir que nossas opiniões e escolhas façam diferença em situações que nos afetam direta ou indiretamente" (p. 14). Por outro lado, o direito à comunicação também é visto, nesse processo, como essencial. Para isso, a base deve ser a comunicação compartilhada. Para vivenciá-la na prática, o material traz a fala do professor Ismar de Oliveira Soares, do Núcleo de Comunicação e Educação da USP, sobre a importância dos espaços educativos:

Vivemos, simultaneamente, em diferentes "espaços educativos", verdadeiras praças de convivência de uma rede que se entrecruza: a família, o grupo de amigos, a escola, a mídia, os diferentes territórios de militância ou de trabalho, a rua, o bairro, a cidade... Esses espaços nos educam ou até podem servir para que exerçamos nossa vocação de educadores. Existem os que já descobriram o potencial de tais espaços, buscando transformá-los em arenas de domesticação. É justamente lá, onde nos cabe exercer a dialética da dialogicidade, transformando cada espaço "educativo" em espaço "educomunicativo". Essa é a maneira de democratizar a comunicação na própria raiz da sociedade. (Entrevista concedida para a elaboração do material, 2010)

E o material aponta os aprendizados adquiridos por meio das práticas educomunicativas, como: organizar e expressar melhor as ideias; trabalhar em grupo; perguntar e ouvir as pessoas; pesquisar sobre diversos assuntos; lidar com o poder; desenvolver um olhar crítico-reflexivo; e trabalhar com tecnologias.

\section{Metodologias sugeridas}

A partir do trabalho realizado, a Viração estabeleceu alguns conceitos-chave que norteiam as metodologias dos diversos projetos educomunicativos. Entre eles estão:

1ํ Foco no processo: tendo como princípio o "aprender fazendo", ou seja, aplicação prática dos conceitos, assim como despertar nas crianças e jovens o sentido de mobilização e transformação, valorizando sempre a diversidade. A avaliação também é fundamental.

2 Gestão democrática interna/externa: vivenciar a democracia, garantindo um processo decisório de forma compartilhada a partir de princípios de colaboração e cooperação.

3ํㅡㄹ Cidade educomunicadora: dar espaço para que todos os saberes - não apenas os que vêm da escolas e da universidade - sejam incorporados nas ações. 
4 Educomunicação entre pares: falar e dar voz num processo educativo de jovens para jovens.

$5^{\text {o }}$ Inter e transdisciplinaridade: privilegiar iniciativas que garantam o compartilhamento de saberes das diversas disciplinas e além delas.

6o Olhar estrangeiro: fomentar iniciativas que permitam aos adolescentes vivenciar e conhecer novos espaços, a fim de que se tornem mais abertos, compreensivos e solidários com a diversidade do mundo.

A organização enfatiza ainda a importância das práticas educomunicativas trabalharem com a leitura crítica da mídia, incentivando crianças e adolescentes a compreenderem o universo da comunicação, assim como com a metodologia conhecida como "coberturas educomunicativas", nas quais o trabalho em grupo, a pesquisa e a diversidade de fontes se sobressaem num processo de produção de informações muito mais colaborativo e que dá voz a todos, garantindo que as pessoas sejam produtoras.

O guia traz também dicas para a produção de matérias de forma educomunicativa, no qual o jovem produtor, antes de elaborar o seu texto para o jornal, por exemplo, apresenta ao grupo as informações levantadas e, em conjunto, discute a melhor forma de apresentar aquela história ao seu público, sempre com responsabilidade e veracidade.

No material, é possível encontrar, ainda, orientações de como produzir notícias para uma Agência Jovem de Notícia, qual é o processo de produção de uma revista ou um fanzine, assim como de um vídeo ou de um blog. Os educomunicadores encontram, por fim, uma proposta de roteiro de como produzir um relato após a atividade, tendo em vista a importância do registro e da sistematização das práticas ${ }^{5}$.

5. Disponível em: <http://issuu.com/portfolio_viracao/docs/ guia_educomunicacao>.

6. MEC. Caderno Pedagógicos Comunicação e Uso de Mídias. Brasília: MEC/Secretária de Educação Básica/Programa Mais Educação, 2011.

\section{CADERNO COMUNICAÇÃO E USO DE MÍDIAS (MEC, BRASÍLIA, 2011)}

Depois de examinarmos duas propostas de manuais, elaboradas no espaço das organizações da sociedade civil, oferecemos à consideração dos leitores um roteiro de reflexões e práticas apresentado aos educadores do país pelo próprio Ministério da Educação (MEC). Trata-se do Caderno Pedagógico "Comunicação e Uso de Mídias”, distribuído sob a responsabilidade da Secretária de Educação Básica/Programa Mais Educação, MEC, a partir de 2011.

\section{Programa Mais Educação}

Para contribuir com o processo de implementação da política de educação integral no país, o governo federal criou o Programa Mais Educação, desenvolvido, desde 2008, pelo Ministério da Educação (MEC). Tal programa contava, na época de sua implantação, com dez áreas interdisciplinares de ação educativa, 
denominadas de "macrocampos", a partir das quais as escolas matriculadas no programa passavam a desenvolver as atividades no contraturno.

Entre os macrocampos encontramos a área da "Comunicação e Uso de Mídias”, que usa o conceito da Educomunicação como referencial teórico e sustentação metodológica. Para orientar as atividades nas escolas, o MEC elaborou uma série de cadernos pedagógicos. O material referente ao macrocampo "Comunicação e Uso de Mídias" contou com a colaboração da Rede CEP Comunicação, Educação e Participação (www.redecep.org.br).

\section{Proposta da publicação}

O Caderno Pedagógico "Comunicação e Uso de Mídias" destina-se a todas as escolas que optam pelo respectivo macrocampo, assim como aos educadores que desejam implementar práticas educomunicativas no ambiente escolar. Levando em conta a expansão do programa pelas cidades brasileiras, elevou-se proporcionalmente, entre 2008 e 2013, o número dos usuários do material. Em 2008, eram 522 escolas, chegando, em 2012, a 6.527 instituições, beneficiando potencialmente mais de 1,2 milhão alunos ${ }^{7}$.

\section{Estrutura do material}

O caderno está dividido em cinco partes:

1․ Analisa a Sociedade da Informação, destacando a influência dos meios de comunicação na produção de sentidos e nas representações sociais.

2a Enfatiza a proposta da educomunicação no Programa Mais Educação, tendo como base os resultados das pesquisas do NCE-USP.

3a Apresenta recomendações para o uso das mídias escolares, a partir da tensão entre o produto (o jornal, o programa de rádio etc.) e o processo ensino-aprendizagem.

4- Traz uma ordem prática para cada uma das mídias propostas pelo Programa Mais Educação no macrocampo.

5 ${ }^{\text {a }}$ Indica caminhos para a articulação das atividades de mídias escolares com as demais áreas e macrocampos de ação do Programa Mais Educação.

\section{Temáticas abordadas}

O caderno traz as principais concepções sobre a proposta da Educomunicação, entendendo-a como "uma nova relação entre educação, educandos e meios de comunicação, que promove o acesso aos veículos de comunicação, estimula a leitura crítica da mídia e a produção de comunicação autêntica por parte dos estudantes".
7. PRÓSPERO, Daniele. Educomunicação e políticas públicas: os desafios e as contribuições para - Programa Mais Educação. Dissertação de Mestrado. Universidade de São Paulo, 2013. 
Destaca que a produção de mídias escolares é uma proposta pedagógica situada no campo do Direito à Comunicação, porque permite que crianças, adolescentes e jovens tenham acesso aos meios de produção, podendo divulgar informações e pontos de vista, dentro de um processo educativo orientado para a autonomia.

O material defende que o uso bem-sucedido de mídias em escolas e comunidades prova que os jornais, a rádio, o vídeo, a fotografia e os quadrinhos produzidos por estudantes de todo o Brasil trazem, no âmago do processo, um fazer interdisciplinar e integrador de tempos e espaços.

No caso dos jornais, por exemplo, há a possibilidade do exercício do texto escrito, que pode ser integrado com uma oficina de produção de quadrinhos, em que a imagem passa, também, a ter um valor na comunicação. $O$ vídeo possibilita a desconstrução e a recriação da linguagem da televisão, tão presente na vida dos estudantes. O rádio exercita a linguagem oral e a capacidade de expressão dos educandos. A fotografia, que traz em si o DNA de toda a leitura imagética da sociedade, por meio da mídia, estará presente em todas as possibilidades de construções conjuntas de comunicação - mas tem valor, por si só, como uma expressão dos educandos.

O caderno aponta, ainda, que os produtos elaborados no ambiente escolar têm potencial de se tornarem parte de um sistema de comunicação entre estudantes, professores, diretores e comunidade escolar, e, portanto, carregam o potencial de instigar diálogos para a construção de um projeto político-pedagógico rico e alinhado às características de uma escola que tenha importância na vida de seus estudantes e da comunidade.

\section{Metodologias sugeridas}

Para que essas questões se façam presentes, o caderno orienta as escolas a promover o exercício da leitura crítica da mídia de massa, um dos pressupostos que garante que as produções das crianças, dos adolescentes e dos jovens tenham de fato um caráter autêntico e inovador. E essa produção deve ser orientada para a autonomia, o protagonismo e o empreendedorismo juvenil, elementos essenciais estimulados pela produção coletiva de comunicação. De acordo com o caderno, as escolas precisam ficar atentas aos seguintes processos na elaboração das mídias escolares: a) definição dos conteúdos; b) aprimoramento dos conteúdos; e c) seleção dos conteúdos.

No primeiro item - definição dos conteúdos -, os educadores precisam garantir uma participação ativa dos alunos na escolha dos temas que farão parte dos programas de rádio, dos roteiros dos vídeos ou dos jornais, por exemplo.

Já em relação ao segundo item - aprimoramento de conteúdos -, enfatiza-se a importância da revisão e correção da produção do aluno, para que ele possa ampliar seus limites, revisando e aprimorando aquilo que já consegue fazer. Essa ação é fundamental também pelo fato de a escola não poder divulgar 
produções que tornem públicas as vulnerabilidades dos alunos, expondo-os a piadinhas. Assim, recomenda-se que o educador organize sequências didáticas, que permitam ao aluno realizar sucessivas revisões e correções de sua produção, com o objetivo de aprimorá-la.

Na última etapa - seleção de conteúdos -, orienta-se como deve ser um processo de escolha dos materiais que serão de fato veiculados, tendo em vista que "ficar de fora" gera frustrações e pode mesmo contrariar os propósitos educativos - que têm como base o uso e a circulação social das produções. Para reduzir os problemas provocados pela necessidade de selecionar (portanto, excluir), uma recomendação é realizar produções cooperativas.

Por fim, em relação à produção, é relevante ressaltar que, nesta perspectiva educomunicativa, o processo em si é mais importante que o produto final. Portanto, a mídia escolar aceita as imperfeições com naturalidade, pois ela é uma produção de uma pessoa em situação de formação. Mas, como já enfatizado anteriormente, não deverá expor os alunos. Por isso, o momento de avaliação e reflexão é tão importante durante a elaboração dos produtos comunicativos ${ }^{8}$.

\section{REFERÊNCIAS}

MEC. Caderno Pedagógicos Comunicação e Uso de Mídias. Brasília: MEC/ Secretária de Educação Básica/Programa Mais Educação, 2011.

PRÓSPERO, Daniele. Educomunicação e políticas públicas: os desafios e as contribuições para o Programa Mais Educação. Dissertação de Mestrado. Universidade de São Paulo, 2013.

PRÓSPERO, Daniele; SOARES, Ismar de Oliveira. Educomunicação e políticas públicas, no Brasil o caso do "Programa Mais Educação". (MEC, Governo Federal), XIII Congresso Internacional Ibercom, Congresso Ibercom, Santiago de Compostela, Espanha, 29 e 31 de Maio de 2013.

SOARES, Ismar de Oliveira. Comunicação/Educação: a emergência de um novo campo e o perfil de seus profissionais. Contato, Brasília, ano 1, n. 1, jan./mar. 1999.

Educomunicação, um campo de mediações. Comunicação \& Educação, São Paulo, ano VII, n.19, set./dez. 2000.

Caminos de la educomunicación: utopias, confrontaciones, reconocimientos. Nomadas, Bogotá, n. 30, abril 2009.

Educomunicação: o conceito, o profissional, a aplicação. São Paulo: Paulinas, 2011.

VIRAÇÃO. Guia de Educomunicação - Conceitos e práticas. São Paulo: 2010.

VOLPI, Mário; PALAZZO, Ludmila (orgs.). Mudando sua escola, mudando sua comunidade, melhorando o mundo! Sistematização da Experiência em Educomunicação. Brasília: Unicef, 2010.

8. Disponível em: <http:// portal.mec.gov.br/index.php?option=com do cman\&task $=$ doc download\&gid=12328\& Itemid=>. 